\title{
Case based Brain Imaging
}

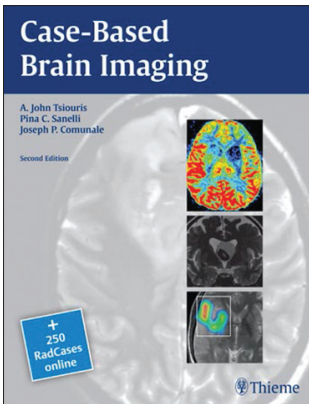

Authors: A J Tsiouris, P C Sanelli, J P Comunale

Publisher: Thieme Medical Publishers

Edition: $2^{\text {nd }}$

Pages: 704 pages, 1292 illustrations

The second edition of Case-Based Brain Imaging (Thieme Publishers; ISBN: 978-1-60406-953-2) is a very good guide for radiology residents, neuroradiology fellows, neurologists, and neurosurgeons, who wish to learn and review their principles of neuroradiologic interpretation. The approach of the book in the case-based format is very much like day-to-day radiology practice scenario where the radiologists get to know the brief clinical history followed by the images. The images are accompanied by a short description of the condition followed by a point-to-point discussion of pathology, differential diagnosis, and the treatment. The case-based format followed by discussion is an excellent method of learning, reviewing, and consolidating the basic principles of neuroradiology. The book serves as a source for quick testing and revision of the principles learnt in day-to-day work.

The book is organized into seven sections and covers the entire spectrum of brainimaging, including neoplasms, inflammatory diseases, cerebrovascular diseases, neurodegenerative/ metabolic diseases, trauma, congenital malformations, and cranial nerves. Each of the sections is divided into subsections for easy and quick referencing. The list of cases covered is fairly comprehensive and describes most of the cases that would be encountered in day-to-day radiology practice.

The images are of excellent quality and of a fairly large size, keeping in view that it is a radiology book. The abnormalities are very well shown and the subtle findings are marked with arrows for easy understanding. The discussion part is concise and to the point, and gives appropriate gradings and classifications wherever suitable. An excellent feature is the inclusion of pearls and pitfalls at the end of every discussion, which a radiology trainee needs to remember to form his/her own diagnostic algorithm.

The book is an excellent source for quick review, especially for exam-going residents and neuroradiology fellows, but surely not a substitute to the core books which are essential to form basic radiology concepts.

Sandeep Jakhere

Asst. Professor. B Y L Nair Charitable Hospital, TN Medical College, Mumbai - 400 008, India. E-mail: drsandeepjakhere@gmail.com

\begin{tabular}{|l|l|}
\hline \multicolumn{2}{|c|}{ Access this article online } \\
\hline Quick Response Code: & Website: \\
\hline & www.ijri.org \\
\hline
\end{tabular}

